\title{
ANÁLISE COMPARATIVA DO PROCESSO DE CONSTRUÇÃO DA POLÍTICA CRIMINAL NO BRASIL E EM PORTUGAL
}

\section{Antonio Henrique Graciano Suxberger ${ }^{1}$ José Wilson Ferreira Lima ${ }^{2}$}

\section{Resumo}

$\mathrm{O}$ artigo analisa o processo de criação da política criminal pelo parlamento brasileiro, que combina elementos de segurança pública com os de direito penal, processual e penitenciário, tratando-os conjuntamente como espécie única de política pública. Avalia os critérios para a construção da política criminal, como produto de decisões que pretendem desafiar os crescentes índices de criminalidade e prometem respeito aos direitos e às garantias constitucionalmente protegidos. $\mathrm{O}$ estudo tem como referencial empírico a "Lei Quadro da Política Criminal" adotada pela Assembleia da República de Portugal, que opera como marco legal dessa atividade no Estado lusitano. Metodologicamente, o estudo se desenvolve na linha teórico-argumentativa e pretende, comparativamente, explorar e analisar como um estatuto específico de produção de políticas criminais pode favorecer a construção de arranjos normativos mais adequados e coerentes como os desenhos institucionais, preservando-se a integridade dos direitos individuais, concomitantemente com a efetivação da segurança pública, assumindo-se que no cenário brasileiro as grandes questões de segurança pública e dos direitos e garantias são retoricamente articuladas pelo discurso populista e de ocasião.

Palavras-chave: Política Criminal; Procedimento Legislativo; Garantias Individuais; Análise Comparativa

\section{INTRODUÇÃO}

No Brasil é perceptível que para cada "onda de criminalidade" anunciada, em regra pelos veículos de comunicação de massa, há um correspondente discurso político produzido no Parlamento, que se lança com propostas para o enfrentamento da criminalidade e se constitui, em termos práticos, em discurso performático e representativo de manifestações acaloradas e oportunistas dos atores políticos. Quase sempre esses discursos são seguidos por um conjunto de

\footnotetext{
${ }^{1}$ Professor do Programa de Mestrado e Doutorado em Direito do Centro Universitário de Brasília (UniCEUB). Professor do Máster Oficial em Direitos Humanos, Interculturalidade e Desenvolvimento da Universidade Pablo de Olavide (Espanha) e Universidade Internacional da Andaluzia. Professor da Fundação Escola Superior do MPDFT (FESMPDFT) e da Escola Superior do Ministério Público da União (ESMPU). Mestre Em Direito, Estado e Constituição (Universidade de Brasília). Doutor em Derechos Humanos y Desarollo (Universidad Pablo de Olavide, Espanha). Pós-doutor em Democracia e Direitos Humanos (Ius Gentium Conimbrigae, Universidade de Coimbra). Promotor de Justiça no Distrito Federal. Centro Universitário de Brasília - UniCEUB.. Brasil. E-mail: Antonio.Suxberger@ceub.edu.br

${ }^{2}$ Doutorando em Direito - UniCEUB. Mestre em Direito Constitucional - IDP. Promotor de Justiça - MPDFT. Centro Universitário de Brasília - UniCEUB. E-mail: wferreiraster@gmail.com
} 
medidas batizadas com nomes sugestivos, como "pacote de segurança pública", que contém projetos legislativos que, se aprovados, poderão ajudar na redução dos índices de criminalidade. É isso o que se tem afirmado, ao menos teoricamente.

A recente e recorrente prática parlamentar tem evidenciado que "pacote de segurança pública" é produção legislativa de ocasião, cuja proposta imediata é atuar sobre os eixos dos cenários político e social i) como resposta aos meios de comunicação, que repercutem, maciçamente, a atividade criminosa desencadeada nos principais centros urbanos, sugerindo, com isso, que o problema da criminalidade sistemática não passa despercebido pelo Parlamento e, também, ii) como resposta ao eleitorado, que precisa ter satisfeita sua necessidade emergencial de controle da crise de segurança, ainda que isso em termos práticos não represente segurança efetiva.

A experiência adquirida sobre o modelo político de resposta à crise da criminalidade no Brasil, com a formulação de "pacotes de segurança pública", permite ao observador mais atento identificar o traço comum destes, que se caracterizam, fundamentalmente, por conterem propostas legislativas para o agravamento de sanções penais ou o (re)enquadramento de alguns crimes como hediondos, a modificação de leis processuais e o agravamento dos regimes prisionais, principalmente no que se refere às privativas de liberdade e à progressão dos regimes. Nessa medida, embora a proposta anunciada refira-se à segurança pública, segundo o viés do controle da criminalidade, o objeto imediato da interferência legislativa recai, preponderantemente, sobre o direito penal, o processual penal e o penitenciário, o que simboliza e marca a crença na segurança pública como produto de reformas legislativas pontuais e de ocasião, ignorando-se, na mesma medida, a própria omissão do Parlamento quanto à produção de leis gerais atualizadas e mais adequadas ao perfil do Estado e da sociedade moderna (DIMOULIS, 2002, p. 42), que ainda têm que conviver com legislações ultrapassadas, a exemplo do Código Penal (1940), do Código de Processo Penal (1941) e da Lei de Execução Penal (1984). Além disso, também seria necessário remodelar o sistema de justiça criminal, em todos os setores de atuação, buscando resolver problema recorrente que se assenta no discurso aberto e conveniente do tipo "agente prende (instância policial) e eles soltam (instância judiciária)”.

Para se ter um suporte empírico, que sirva de referencial exemplificativo quanto a essa discussão, será objeto de exame o "pacote de segurança pública" recebido pelo Senado Federal (SF) em novembro de 2017, composto por cinco projetos de leis (PL) da Câmara dos Deputados (CD), de onde tiveram origem, com a finalidade de "endurecer a legislação sobre a segurança pública" 
(BRASIL, 2017a): i) o Projeto de Lei da Câmara (PLC) 140/2017 exclui do Código Penal a atenuante para os autores de crimes entre 18 e 21 anos de idade, assim como exclui a redução do prazo de prescrição para menores de 21 anos (BRASIL, 2017b); ii) o PLC 141/2017 torna obrigatório que as empresas de telefonia e as operadoras de serviço móvel pessoal instalem bloqueadores de sinais de telecomunicações, de radiocomunicações e de Internet nos estabelecimentos penais e socioeducativos (BRASIL, 2017c); iii) o PLC 143/2017 determina que em relação aos crimes de genocídio o regime prisional será integralmente fechado e, quanto aos crimes hediondos de que trata o art. $2^{\circ}$ da Lei n. 8.072/1990, a progressão do regime prisional ocorrerá com o cumprimento de metade da pena para os condenados primários e com o cumprimento de dois terços da pena para os condenados reincidentes (BRASIL, 2017d); iv) o PLC 144/2017 institui a Política Nacional de Busca de Pessoas Desaparecidas e cria o cadastro nacional de informações, públicas e sigilosas, além de dispor sobre a cooperação entre órgãos de segurança pública e outras entidades, a capacitação de agentes públicos, o atendimento psicossocial, as medidas de investigação e as de divulgação de alertas (BRASIL, 2017e), e v) o PLC 146/2017 determina que a saída temporária de detento não poderá ser superior a quatro dias, embora possa ser renovada mais de uma vez durante o ano, e somente será concedida por ato motivado do Juiz da execução, ouvido o Ministério Público, e mediante parecer favorável da administração penitenciária, além de depender da satisfação de alguns requisitos (BRASIL, 2017f).

Servirá, ainda, como modal comparativo a Lei n. 17/2006, aprovada pela Assembleia da República de Portugal, conhecida como "Lei Quadro da Política Criminal”, a qual dispõe sobre a condução da política criminal naquele país, funcionando como espécie de "estatuto básico para a elaboração dessa política", tendo, especificamente, a finalidade de dispor sobre a definição de objetivos e prioridades e, destacadamente, a de atuar como instrumento legal de orientação em matéria de prevenção da criminalidade, investigação criminal, ação penal, execução das penas e medidas de segurança. Entre os principais aspectos dessa lei, que serão analisados no presente estudo, é importante ressaltar a definição de limites, assim como a audição prévia de todos os setores do Estado que têm interesse e atuam na aplicação da política criminal, não se podendo ignorar que a "análise das políticas públicas não serve para propor novas soluções para os problemas sociais, mas para compreender como tais problemas são encarados pelos agentes públicos" (GERALDO, 2012, p. 2).

Sob esse enfoque, pode-se partir da perspectiva genérica de que a análise da política além de servir a sua própria compreensão, também favorece o aprimoramento dos arranjos vol.12, nº.03, Rio de Janeiro, 2019. pp. 588-611 
institucionais, ante ao reconhecimento, por exemplo, de suas fragilidades em cada setor do sistema de segurança. Assim, uma vez que políticas públicas são escolhas, sua análise pode ter como objetivos descrever e investigar como e porque foram propostas, adotadas e implementadas, sendo este o lado teórico de seu estudo. Devido a isso, a opção política deve ser avaliada à luz do que as análises revelam sobre as chances de serem adotadas, sua efetividade provável ou impactos resultantes e também as dificuldades de implementação (COCHRAN, 2012, p. 8). Dito de outro modo, o estudo analítico de políticas públicas objetiva entender como decisões das autoridades são feitas e executadas em favor da sociedade (CRUMPTON, 2016, p. 986). Analiticamente, o instrumento da política pública revela a teorização que envolve governantes e governados e, nesse sentido, representa que toda ela constitui instrumento condensado e finalizado sob a forma de conhecimento acerca do controle social e dos meios de executá-lo (LASCOUMES; LE GALES, 2007, p. 11).

\section{DA POLÍTICA PÚBLICA À POLÍTICA CRIMINAL}

Por certo, o primeiro passo para o tratamento da política criminal é o seu reconhecimento como espécie do gênero mais amplo e diversificado que é o da política pública, que pode abarcar incontáveis possibilidades de áreas especializadas em que o Estado deva atuar, desde o planejamento e execução até a avaliação final de resultados. Entre as várias possibilidades, a política pode ter como objetos de atuação áreas como a saúde, a educação, a defesa, a segurança pública, as relações exteriores, o meio ambiente, a tributação, a previdência, a habitação, a economia, a infraestrutura, o comércio, as minorias, o trabalho etc., podendo-se sintetizar que "a área de políticas públicas é perpassada por uma variedade de disciplinas, instituições e executores, abrangendo diversas questões, necessidades e pessoas (TREVISAN; BELLEN, 2008, p. 535). Mas, em qualquer desses setores específicos, estará sempre envolvida pela atuação do governo, a quem cumpre a função de planejamento e execução coordenada das ações (BUCCI, 2013, p. 33), de modo que para se alcançar efetividade e regular continuidade é imperioso que regramentos e definições não sejam dados aleatórios tomados ocasionalmente e sem nenhum controle finalístico, mas que sejam lastreados por uma sistematização teórica de abordagem das políticas públicas, com o que se pretende contribuir, não ocasionalmente e sem critérios, para a criação de fórmulas dirigidas para a organização e estruturação do Poder público, condizentes com suas finalidades e para que sejam capazes de melhorar sua intervenção. Essa sistematização teórica tem a pretensão de tornar a ação estatal mais efetiva, racional e compreensível, além de subsidiar juridicamente a análise e a formulação das políticas públicas (BUCCI, 2013, p. 37). 
Para além disso, a política pública não se reduz a mero ato político. Sua sede institucional são os aparelhos do Estado, que detêm o poder de decisão, a partir e com os quais se controlam os mecanismos da legislação e de repressão (DIMOULIS, 2002, p. 41). Trata-se de atividade complexa, para a qual convergem os três principais modais da atividade estatal: i) é modalidade administrativa que surge com a escolha da política pública a ser criada, a forma como será implementada e, mais adiante, alcança os processos avaliativos aos quais será submetida, especialmente orientados para a apuração de possíveis benefícios; ii) é, também, atividade dependente da atuação legislativa, como componente necessário na criação de leis e atos normativos reputados necessários para dar forma e amparo jurídicos ao programa de ação estatal escolhido, e, finalmente, iii) tem-se a atuação judicial (externa) nos casos em que a política pública é submetida ao controle e à avaliação de correspondência com sua proposta inicial e suas finalidades constitucionais e legais (MURDA, 2015, p. 44). Nesse sentido, entende-se que as políticas públicas são atividades de natureza administrativa e complexa, que se destinam à promoção de prestações que visam o interesse comum, compreendendo o exercício de todas as funções estatais para sua formulação e implementação (MURDA, 2015, p. 42). Sob esse enfoque, admitindo-se as políticas públicas antes como deliberações políticas, e não propriamente jurídicas, cumpre ao Poder Legislativo sua formulação legal a partir das normas constitucionais de cunho social e ao Poder Executivo sua concretização, mediante a implementação material das prestações estatais legalmente positivadas. Mais adiante, a depender das circunstâncias, a intervenção do Poder Judiciário poderá ser demandada, para dirimir eventuais conflitos decorrentes (MORAIS; BRUM, 2016, p. 21) e até mesmo para atuar no processo de avaliação, se necessário.

Disso decorre, naturalmente, que o poder é elemento básico para a implementação das políticas, de modo que, redundantemente, as políticas públicas se constituem das próprias decisões do governo. Nessa medida, assumindo-se que são decisões das mais importantes tomadas no âmbito do poder governamental, poderá haver equilíbrio ou desequilíbrio quanto à parte da decisão que competir ao Legislativo e a parte que competir ao Executivo (DIAS; MATOS, 2012, p. 5), mesmo considerando que sua consistência e efetividade pressupõem e exigem a "unidade", ainda que no contexto de conflitos e diversidades (MOUFFE, 2003, p. 114). Nessa ordem, convém destacar que "a realidade política de quase todas as democracias acarreta uma integração do Legislativo com o Executivo, afiançando a existência de poderes coordenados" (BONAVIDES, 2011, p. 138), expectativa que deve ser considerada ao menos teoricamente. 
Com isso, apesar do conteúdo político próprio dessa atividade estatal, é preciso ter em vista que administradores e gestores públicos em geral necessitam de um arcabouço jurídico que seja minimamente flexível e permita a realização de experimentações e revisões, sem prejuízo de assegurar a prestação de contas e o controle democrático (COUTINHO, 2013, p. 188), entendendose que essa flexibilidade implica que nenhuma política pública está isenta de questionamentos e de revisões judiciais (COUTINHO, 2013, p. 190). Devido a isso, o direito objetivo pode fazer com que as políticas públicas sejam mais democráticas, sujeitando-as aos mecanismos de participação e accountability, além de estimular a atuação plural dos atores políticos (COUTINHO, 2013, p. 197) e, nessa medida, o direito pode atuar como (re)tradutor das demandas públicas e da construção das respostas possíveis.

De qualquer maneira, tratando-se de políticas públicas, é importante garantir que os objetivos de interesse público não sejam sacrificados pela alternância de poder, essencial à democracia, e que os processos de realização dos objetivos ou metas fixadas se submetam aos parâmetros estabelecidos em lei (BUCCI, 1997, p. 97), o que para alguns autores é tratado como “quadro geral de ação" (BARCELLOS, 2016, p. 118). Devido a isso, uma vez que o advento do constitucionalismo colocou em pauta as importantes discussões dos textos constitucionais indicadores dos fins, objetos e projetos amplos para a sociedade, e que em países como o Brasil, cuja marca definidora são as promessas não atendidas de modernidade, é fundamental deixar clara a relação que vincula a Constituição às políticas públicas (OHLWEILER, 2007, p. 274), especialmente no espaço no qual se insere o debate sobre a definição, elaboração e concretização da política criminal, pois, de acordo com Binder, é preciso construir um conhecimento que permita racionalizar o poder punitivo do Estado, sendo esta a tarefa da política criminal, enquanto política pública que administra e organiza a violência do Estado, constituindo-se em importante atividade estatal (BINDER, 2006, p. 50). Para Binder, não é possível transpor as categorias próprias do direito penal para a análise da política criminal, entendendo que a análise política toma como referência os elementos da tecnologia governamental (BINDER, 2006, p. 51). Nessa ordem, explica que o desenho da política criminal funciona em sentido inverso, pois a categoria do crime não serve, porque não se pode conceber uma política criminal da mesma maneira que se pretende controlar o mercado de veículos roubados ou os ilícitos praticados no mercado de capitais ou, ainda, os relacionados com a violência doméstica e assim por diante. Portanto, é a análise da política criminal que deve fornecer à política pública os conceitos adequados para projetá-la corretamente e torná-la mais precisa (BINDER, 2006, p. 52). Ademais, concordando com esse entendimento, e 
considerando que a noção formal-liberal que deu origem ao constitucionalismo fazia crer num Estado mínimo, onde o conteúdo da Constituição era basicamente o teor das garantias, isto é, a proteção do indivíduo, sua liberdade e seus direitos (SALDANHA, 2000, p. 115-116), não estaria a política criminal que se pratica nos dias de hoje atuando em oposição aos direitos e às garantias fundamentais, portanto, contrariando a essência da Constituição?

\section{ABRINDO O "PACOTE DE SEGURANÇA PÚBLICA"}

Conforme registrado anteriormente, o "pacote de segurança pública" anunciado pelo Senado Federal em novembro de 2017 continha um conjunto de leis que poderá alterar penas, modificar o tempo para a progressão de regimes carcerários, além de suprimir alguns benefícios previstos na legislação penal/processual penal em vigor.

Tabela 1 - Descrição de projetos de leis do "pacote de segurança pública" (2017).

\begin{tabular}{|c|c|c|c|}
\hline \multicolumn{4}{|c|}{ PACOTE DE SEGURANÇA PÚBLICA } \\
\hline \multirow{3}{*}{ PR } & SITUAÇÃO ATUAL & ORIGEM & DATA DE APRESENTAÇÃO \\
\cline { 2 - 4 } OJ & PLC 140/2017 SF & PL 2862 CD & 20 jan. 2004 \\
\cline { 2 - 4 } ET & PLC 141/2017 SF & PL 3019 CD & 16 set. 2015 \\
\cline { 2 - 4 } OS 143/2017 SF & PL 8504 CD & 05 set. 2017 \\
\cline { 2 - 4 } & PLC 144/2017 SF & PL 6679 CD & 22 dez. 2009 \\
\cline { 2 - 4 } & PLC 146/2017 SF & PL 3468 CD & 15 mar. 2012 \\
\hline
\end{tabular}

Fonte: Proposições legislativas do Senado Federal.

Todos esses projetos foram iniciados na Câmara dos Deputados, em datas e com finalidades variadas, sendo que nenhum foi proposto com o objetivo específico e imediato de compor o mencionado "pacote de segurança pública". Analisados separadamente, cada projeto pode ser descrito nos seguintes termos:

i) PLC 140/2017 SF: em sua redação original, o projeto revogava o art. 115 do Código Penal (CP), ao argumento de acabar com os privilégios previstos no referido dispositivo. Contudo, sua redação foi alterada, passando a dispor que a atenuação da pena (art. $65, \mathrm{I}, \mathrm{CP}$ ) e a redução do prazo prescricional à metade somente se aplicarão ao agente que for maior de setenta anos de idade na data da sentença, excluindo de tais benefícios o agente menor de vinte e um anos de idade na data do fato. O projeto foi apresentado em janeiro de 2004 e somente em abril de 2018 recebeu designação de relator. Encontra-se, atualmente, na Comissão de Direitos Humanos e Legislação Participativa.

ii) PLC 141/2017 SF: pelo projeto em questão, as empresas de telefonia e as operadoras de serviço móvel pessoal serão obrigadas a instalar equipamentos com tecnologia para bloquear sinais de telecomunicações e radiocomunicações nos estabelecimentos penais e nos de execução de medidas socioeducativas, de modo a impedir a comunicação por telefones móveis e Internet por detentos e menores apreendidos, mantidos nesses estabelecimentos prisionais. $\mathrm{O}$ 
projeto foi apresentado em setembro de 2015 e encontra-se na Comissão de Constituição, Justiça e Cidadania, onde aguarda a designação de relator ( $1^{\circ}$ nov. 2018).

iii) PLC 143/2017 SF: o projeto introduziria alterações na Lei n. 8.072/1990, passando a dispor que o cumprimento das penas quanto aos crimes de lesão corporal dolosa de natureza gravíssima e de lesão corporal seguida de morte, quando praticados contra autoridade ou agente descrito nos arts. 142 e 144 da Constituição Federal, integrantes do sistema prisional e da Força Nacional de Segurança Pública, no exercício da função ou em decorrência dela, ou contra seu cônjuge, companheiro ou parente consanguíneo até terceiro grau, em razão dessa condição, será integralmente fechado. O referido projeto foi apresentado em setembro de 2017 e, no Senado Federal, foi rejeitado e arquivado.

iv) PLC 144/2017 SF: o projeto cria o Cadastro Nacional de Pessoas Desaparecidas, tendo como fundamento que o desaparecimento de pessoas no Brasil é fenômeno pouco compreendido em suas causas, estimando-se que aproximadamente $15 \%$ dos casos conhecidos permanecem sem solução. O projeto foi apresentado em dezembro de 2009 e aguarda deliberação do plenário do Senado Federal (12 nov. 2018).

v) PLC 146/2017 SF: o projeto impede que condenados que estiverem cumprindo penas no regime semiaberto obtenham autorização de saída temporária sem vigilância direta, como nos casos de visita à família, justificando-se que tal circunstância tem feito a sociedade refém da violência de apenados que obtêm esse benefício. Justificou-se tal medida, porque a saída temporária contribui para o aumento da violência e da intranquilidade social. O projeto foi apresentado em março de 2012 e encontra-se na Secretaria Legislativa do Senado Federal (25 jun. 2018).

\section{LEI QUADRO DA POLÍTICA CRIMINAL EM PORTUGAL}

O Estado de Portugal adotou a Lei n. 17/2006, conhecida como "Lei Quadro da Política Criminal” (LQPC), como guia de sistematização geral para a elaboração, execução e avaliação da política criminal naquele país (PORTUGAL, 2006, p. 3462-3463). A referida lei destina-se a servir como marco regulador da criação e desenvolvimento da legislação subsequente voltada para o enfrentamento da criminalidade, encontrando-se organicamente dividida em cinco capítulos e contando com apenas dezesseis artigos. E, apesar da concisão, seu mérito é o de dispor de forma abrangente e sistematizada sobre os tópicos essenciais que devem estar presentes numa lei de regência da política criminal. Desse modo, sua concisão é compensada pela riqueza e detalhamento de seu conteúdo.

A LQPC encontra-se estruturada em capítulos especializados pelo conteúdo, devidamente concatenados, o que lhe assegura coerência temática e consistência. Com isso, em sua parte introdutória, a lei definiu que a condução da política criminal deve abranger a definição de objetivos e as prioridades a serem alcançadas, além de fixar orientações em matéria de prevenção da criminalidade, investigação criminal, ação penal, execução de penas e medidas de segurança. Nesse contexto, todavia, fixou limites claros de que a definição de objetivos e das prioridades e a orientação na formulação da política criminal não podem prejudicar o princípio da legalidade, a independência dos Tribunais e a autonomia do Ministério Público, como também não podem conter 
diretivas, instruções ou ordens sobre processos criminais em particular, sendo vedado isentar de procedimento qualquer crime (Capítulo $\mathrm{I}$, arts. $1^{\circ}$ e $2^{\circ}$ ).

No passo seguinte, a LQPC estabeleceu que a política criminal deve ser congruente e observar os valores protegidos pela Constituição e leis que disponham sobre bens jurídicos (Princípio da Congruência), como também deve ter por objetivos a prevenção e a repressão da criminalidade, assim como a reparação de danos, individuais ou sociais, atendendo-se às necessidades concretas para a defesa dos bens jurídicos. Ademais, quanto ao bem jurídico tutelado, à respectiva norma que o prevê, ao modo de execução, aos resultados, aos danos individuais e sociais e à penalidade, reconhece que são fatores que podem servir como parâmetros indicativos dos crimes que devem ser tratados com prioridade nas correspondentes ações preventivas e investigativas. Mas, para tanto, as opções eleitas como prioridades devem ser fundamentadas. Com isso, ao lado das escolhas definidas como prioritárias, impõe-se observar que as orientações da política criminal podem estabelecer a indicação de tipos penais em relação aos quais se justifique, por exemplo, a adoção de medidas diferenciadas, como a suspensão do processo, o arquivamento, a isenção de pena, o processo sumaríssimo e o julgamento do processo quando a pena for superior a cinco anos ou nos casos de pequena criminalidade (Capítulo II, arts. $3^{\circ}$ ao $6^{\circ}$ ).

Nos termos definidos pela LQPC, há distribuição de atribuições entre as instituições públicas, visando a elaboração de leis que disponham sobre a política criminal. O primeiro momento para a elaboração de uma lei dessa natureza ocorre com a audiência prévia dos Conselhos Superiores da Magistratura, do Ministério Público, da Segurança Interna, do Gabinete Coordenador de Segurança e da Ordem dos Advogados. Após ouvir cada um desses setores, o Governo (Poder Executivo), a quem compete a condução da política criminal, submete à Assembleia da República a proposta de lei, contento os objetivos, as prioridades e as orientações a serem seguidas em termos da política criminal. As propostas devem ser apresentadas a cada dois anos, até o dia 15 de abril, sendo este o período de vigência dessas leis. Assim, competirá à Assembleia da República aprovar as leis sobre a política criminal, como decorrência do exercício de sua atividade política, mas não antes de ouvir o Procurador-Geral da República, que se manifestará acerca da execução das leis de mesma natureza que ainda estiverem vigor. De qualquer modo, a Assembleia da República poderá introduzir alterações aos objetivos, às prioridades e às orientações propostas em termos de política criminal, quando se iniciar nova legislatura ou se modificarem, substancialmente, as circunstâncias que embasaram a aprovação da lei sobre a política criminal em curso (Capítulo III, arts. $7^{\circ}$ ao $10^{\circ}$ ). 
No âmbito da execução, competirá ao Ministério Público e aos órgãos policiais assumirem os objetivos propostos e adotarem as prioridades e as orientações fixadas na respectiva lei, assim como a estes e também aos órgãos da Administração Pública competirão a prestação de apoio para as ações de prevenção e de investigação criminal, especialmente na distribuição de recursos humanos e materiais, de modo a atender aos objetivos, às prioridades e às orientações definidas na lei de política criminal. Ao Governo cumprirá emitir diretivas, ordens e instruções destinadas a fazer cumprir a lei, assim como ao Procurador-Geral da República no âmbito dos inquéritos e das ações de prevenção sob a responsabilidade do Ministério Público.

Por derradeiro, visando à avalição da política criminal, competira ao Governo apresentar à Assembleia da República, até o dia 15 de outubro de cada ano, relatório que disponha sobre sua execução, especificamente em matéria de prevenção da criminalidade e execução das penas e medidas de segurança. Do mesmo modo e no mesmo prazo, cumprirá ao Procurador-Geral da República apresentar ao Governo e à Assembleia da República relatório sobre a execução das leis de política criminal, em relação aos inquéritos e às ações de prevenção no âmbito da competência do Ministério Público, circunstanciando as dificuldades verificadas, com a indicação dos modos de as superar, podendo a Assembleia ouvir o Procurador-Geral para obter esclarecimentos sobre o relatório por ele apresentado (Capítulo IV, arts. $11^{\circ}$ aos $14^{\circ}$ ).

Portanto, atendendo aos limites constitucionais, a LQPC é o instrumento normativo que atua como marco regulatório para a elaboração, a execução e a avaliação de políticas criminais em Portugal, servindo de parâmetro para a análise dessas políticas, na medida em que abarcou todas as funções envolvidas pelo sistema de justiça criminal, principalmente mediante a distribuição de atribuições e a fixação de limites de atuação dos diversos atores e instituições.

Assim, em consonância com a descrita LQPC, a Assembleia da República de Portugal editou a Lei n. 51, de 31 de agosto de 2007, cuja finalidade foi definir os objetivos, as prioridades e as orientações de política criminal para o biênio de 2007-2009 (PORTUGAL, 2007, p. 60576062). Acompanhando a referida lei, sob a forma de anexo, consta um texto específico intitulado "Fundamentação das prioridades e orientações da política criminal", que contém todo o embasamento da política criminal que deverá ser implementada e seguida em Portugal, podendo-se destacar, entre outras diretivas, que:

Os crimes escolhidos como alvos preferenciais das orientações sobre a criminalidade são relativamente pouco graves - puníveis, em regra, com prisão 
até 3 anos ou com pena de limite máximo inferior - e têm consequências susceptíveis de reparação, em grande parte dos casos.

No âmbito dos crimes contra as pessoas, são objeto destas orientações a ofensa à integridade física simples e os crimes pouco graves contra a liberdade, contra a liberdade sexual e contra a honra. Também o aborto com consentimento da mulher grávida, fora das situações de não punibilidade legalmente previstas, é objeto destas orientações, tendo em conta que a prisão efetiva não possui um efeito ressocializador.

Os crimes contra o patrimônio menos graves, a criminalidade rodoviária menos grave e a emissão de cheque sem provisão justificam, de igual modo, este tratamento processual.

Por último, também a figura do consumidor-traficante justifica a aplicação de orientações sobre pequena criminalidade, tanto mais que a Lei n. 30/2000, de 29 de novembro, descriminalizou o consumo de estupefacientes, convertendo-o em ilícito de mera ordenação social.

Por vezes, as situações de pequeno tráfico instrumental do consumo reclamam, acima de tudo, uma intervenção terapêutica e não a punição pura e simples (PORTUGAL, 2007, p. 6062).

\section{RUMOS DA POLÍTICA CRIMINAL NO BRASIL}

A partir desse conjunto de informações sobre a condição teórica e prática da política criminal, enfocada segundo planos estatais diferenciados - Brasil e Portugal -, é possível avaliar e considerar que, primeiramente, essa política não constitui problema exclusivo do Brasil e, segundo, que há alternativas técnicas para o enfrentamento da criminalidade que não a adoção de medidas momentâneas, empobrecidas por discursos oportunistas, de reduzido valor técnico e flagrantemente ofensivos ao regime democrático e ao próprio Estado de Direito. Ademais, é do modelo de Estado que se deve extrair a política criminal como produto para a obtenção e a realização de critérios diretivos no âmbito da justiça criminal (MUÑOZ TEJADA, 2009, p. 16), pressupondo-se ser uma política mais didática (como fazer) do que propriamente mera reunião de atos normativos-punitivos.

Paralelamente a isso, de acordo com pesquisadores do International Centre for the Prevention of Crime (ICPC) no Canadá, também se insere nesse contexto, de forma irrenunciável, a necessidade de se fazer a prevenção criminal e o combate à violência policial como meios de resgate da cidadania e de suportes para o adequado desenvolvimento das políticas sociais em geral. Nesse aspecto, a prevenção do crime por meio do desenvolvimento social inclui vasta gama de abordagens sociais, educacionais, de saúde, culturais, ambientais etc., que podem ajudar a reduzir os riscos de ofensas e vitimizações e reforçar os fatores de proteção, entendendo-se que as abordagens sociais em geral se baseiam em formas concretas de políticas que ofereçam apoio às populações em áreas mais vulneráveis (IDRISS, 2010, p. 2). De fato, as pesquisas no campo social têm demonstrado que as desigualdades sociais e a violência das abordagens policiais aumentam o 
nível de insegurança dos cidadãos, o que impõe a promoção de instituições de segurança fortes, mas, se exigindo delas o uso disciplinado da autoridade policial, além da reconstrução da segurança do cidadão (FERNANDO, 2014, p. 75).

Devido a isso, a forma sobre "como se produz" a política criminal no Brasil deve ser objeto de exploração acadêmica, não apenas em razão de seu conteúdo reflexivo, mas especialmente propositivo. Dessa maneira, a primeira e importante discussão versa sobre o conteúdo garantista da política criminal, pois acerca desse aspecto tem-se argumentado que os garantistas mantêm o foco do garantismo penal na proteção dos direitos individuais, ao passo que os seus adversários, ao contrário, defendem a prioridade do controle penal e valorizam as funções da pena, que atuaria como instrumento de inibição do crime (GUINDANI, 2006, p. 5).

Nessa medida, entende-se que as políticas deveriam ser projetadas e implementadas dentro da lei e do quadro institucional do país, e também ser democráticas em forma e conteúdo, além de garantirem os direitos de todos. Ou seja, as políticas deveriam respeitar a Constituição, os princípios democráticos e os tratados internacionais, sem prejudicar a capacidade de agir das instituições. Não sendo assim, qualquer política que pretendesse alcançar níveis de segurança ao diminuir os direitos e as liberdades individuais seria ineficaz e ofenderia aos princípios que inspiraram os países de hemisfério ocidental (ORGANIZATION OF AMERICAN STATES, 2008, p. 64), o que representa e configura, em tese, política antigarantista.

Com isso, acolhendo a política criminal como expressão da política pública, percebese que essa atividade representa aquilo que os governos deveriam fazer para melhorar o padrão de vida das pessoas e também os esforços para enfrentar desafios, tais como a insegurança, a falta ou a precariedade de infraestrutura e o desemprego, entre outros (NWAGBOSO, 2012, p. 61-62). Se for assim, restaria definir se seria democrático e respeitoso à Constituição a adoção de políticas antigarantistas como forma de enfrentamento da criminalidade. E mais, nesse mesmo contexto, admitindo-se a política pública (sentido amplo) como aspecto central do processo político, ela somente se legitimaria como tal desde que fosse submetida a todas as etapas regulares do procedimento de produção das políticas estatais, que inclui a iniciação ou formação, a implementação e a avaliação (NWAGBOSO, 2012, p. 62). Então, a política criminal brasileira (sentido estrito), que fosse estabelecida mediante a reunião de um conjunto de leis e anunciada como "pacote de segurança pública", poderia ser efetivamente tratada como tal? E se fosse, lhe caberia o enquadramento como política criminal garantista ou populista? 
Diante de tais questionamentos, é importante situar que a análise apriorística da política criminal quase sempre alcança o debate sobre o populismo e a vocação punitiva dos Estados. Nessa linha, sustenta-se que o populismo encerra um mito, com o qual se pretende resolver os diversos problemas sociais através da "magia dos discursos" e de suas representações, o que implica envolver o povo com o poder político, garantindo-lhe o impossível (MUÑOZ TEJADA, 2009, p. 26). Nesse contexto, o chamado populismo punitivo refere-se ao uso do direito penal pelos governantes, caracterizado por três marcas: i) assume-se a concepção de que o agravamento das penas pode reduzir os crimes; ii) as penas ajudam a reforçar o consenso moral existente na sociedade e iii) há pretensões eleitorais presentes nesse uso (MUÑOZ TEJADA, 2009, p. 32).

Para ajudar nas reflexões e reforçar argumentos, convém aferir o quadro estrutural de construção de políticas públicas (gênero) na perspectiva de Ashley Snowdon, pois, sob sua análise, o processo de desenvolvimento dessas políticas deve abarcar cinco etapas ou fases: i) Problem Definition: impõe que se examine a natureza do problema e se explore as possibilidades de sua resolução (que devem ser específicas); ii) Agenda Setting: uma vez que o problema tenha sido definido e a solução identificada seja viável, deve-se elaborar uma agenda que reúna e organize os meios disponíveis que poderão ser empregados para fundamentar a decisão e influenciar os agentes públicos (tomadores de decisões, gestores, policy makers e lawmakers); iii) Policy Adoption: é o estágio no qual os decisores avaliam as opções, discutem-nas e adotam ou modificam a política proposta; iv) Implementation: uma vez que a política foi aprovada, ela deve ser implementada pelos agentes responsáveis, como administradores, policiais, dirigentes escolares etc., e v) Evaluation: adotada e implementada, é importante saber como a política está se desenvolvendo e quais os resultados obtidos. A avaliação, como etapa indispensável do processo de construção de políticas públicas, pode e deve ser empregada como técnica para aferir o nível de efetividade alcançado (SNOWDON, 2004, p. 3). De modo semelhante a esse modelo de etapas, o ciclo de políticas públicas pode apresentar a fase inicial de formação, na qual são abordados os processos de definições e escolhas dos problemas, que por suas características justifiquem a intervenção estatal, assim como a produção de soluções; no passo seguinte, tem-se a implementação, que representa a execução das decisões anteriormente definidas e, ao final, segue-se a avaliação, que tem a finalidade de atuar na investigação sobre o impacto da política (LIMA; D’ASCENZI, 2014, p. 51).

Observe que, a se considerar esses critérios e ao se confrontá-los com o "pacote de segurança pública", assumido como política criminal pelo Senado Federal brasileiro, chega-se a mesma conclusão obtida por Maurício Zanoide, que sustentou, em linhas gerais, que no Brasil não 
há política criminal, mas apenas "pequenos impulsos ou aparentes tentativas, sempre embebidas por forte influxo autoritário" (MORAES, 2006, p. 416). Tangenciando esse ponto de vista, Gloeckner enfatizou que as leis penais atuam mediante o agravamento extraordinário das penas e da necessidade de relativização dos direitos humanos dos acusados, como estratégia de controle dos índices de criminalidade e sob o pretexto de realização da vontade popular (GLOECKNER; RAMOS, 2017, p. 256).

Em síntese a esse conjunto de reflexões, que enlaçam a formulação da política criminal e a atuação política de ocasião, Romina Rekers referiu-se ao "populismo penal" como conjunto de medidas legislativas de natureza penal, que privilegiam as demandas majoritárias da opinião pública, as vítimas e os setores sociais, que se identificam como potenciais vítimas, sobre os limites normativos consagrados pelas Constituições. Considerou, ainda, que o populismo evidencia como meta o "objetivo eleitoral”, que resulta em se privilegiar os interesses e as opiniões de alguns grupos em detrimento das garantias devidas aos destinatários da aplicação das penas (REKERS, 2012, p. 8). Por esse ângulo, afirma-se que o direito penal, enfocado segundo a concepção positivista, implica na realização do direito penal máximo, expressão da discricionariedade do Estado no exercício do poder punitivo que, por exercê-lo em padrões excessivamente abrangentes, sacrifica as garantias penais mais essenciais (FREITAS, 2002, p. 206).

Ao lado disso, é preciso considerar que o correto planejamento da política pública, em sentido geral, redunda em qualificá-la como ferramenta de gestão (caráter instrumental), o que significa dizer que a identificação quanto às necessidades de políticas e de programas estatais, passando pela especificação dos problemas sociais e pela determinação das lacunas de respostas governamentais ou da inadequação dessas respostas, constitui-se numa das principais formas pelas quais a análise da política pode auxiliar na atuação dos gestores governamentais (CRUMPTON, 2016, p. 985), de sorte que a pesquisa de avaliação desempenha papel significativo em termos de responsabilidade (pública), entendendo-se que a análise das políticas produzidas evidencia a responsabilidade interna, que aponta para a produtividade da intervenção dentro do setor político ou de uma organização (CRUMPTON, 2016, p. 986).

Sob esse ponto de vista, como se pode admitir que exista política criminal no Brasil limitada à reunião de alguns projetos legislativos, em momentos específicos, quando ocorrem anúncios persistentes de descontrole dos níveis da criminalidade, que são sistematicamente publicizados, sem que se tenha debate aprofundado, qualificado e orientações definidas, que possam 
servir de moldura e de conformação para o desenvolvimento da política criminal? Cumpre observar que a argumentação mais simplista em voga sustenta que as explicações sobre a violência e o crime não são fáceis e que, acima de tudo, deve-se evitar a generalização, entendendo-se que o crime não existe no singular e que há imensa diversidade de práticas criminosas associadas a dinâmicas sociais distintas (SOARES, 2007, p. 93). Logo, ao contrário de Portugal, que dispõe de legislação específica sobre a elaboração das leis que disponham sobre política criminal, como se pode conceber que no Brasil se faça esse tipo de política ancorando-se na pressão midiática, principalmente, a qual expõe a todo tempo a elevação dos níveis da criminalidade, especialmente nas áreas urbanas das grandes cidades, como reflexo direto da falta ou da precariedade das políticas públicas nos demais setores da organização social?

Indiscutivelmente, o "pacote de segurança pública" anunciado pelo Senado Federal no ano de 2017 (já se passou um ano e o referido pacote ainda não foi concluído), não observou as etapas relacionadas por Ashley Snowdon, balizadoras dos processos constitutivos das políticas públicas, de modo que essa particularidade quanto ao modo de fazer revelou e expôs a retórica política sugestiva da aplicação de instrumentos supostamente eficazes, mas que em termos práticos apenas se pautaram na elaboração de propostas legislativas que, não raramente, ofendem à Constituição, seus princípios estruturantes e os mais diversos tratados internacionais (RAAD, 2006, p. 4). Além disso, o discurso que se fundamenta no emprego do direito penal como subsídio para a adoção de políticas criminais, quando aplicado à realidade, tem o efeito de produzir seletividade, uma vez que a criminalização ou seu endurecimento tem a propriedade de alcançar os integrantes das classes socioeconômicas mais deficientes (RAAD, 2006, p. 5), o que significa dizer que o "sistema penal produz seleções e, ao selecionar, reforça juízos de atribuição existentes na sociedade" (DUARTE, 2002, p. 102), passando a se caracterizar, nesse ponto, como indutor de desigualdades.

Com isso, a interpretação a que se chega sobre os discursos políticos-penais e a retórica da segurança é que se tem cada vez mais aperfeiçoada a linguagem de guerra contra a criminalidade e os criminosos, que passam a ser considerados inimigos públicos (RAAD, 2006, p. 9). Sob esse enfoque, o que há, verdadeiramente, são ataques diretos à Constituição e aos seus princípios, de forma velada, mas instrumentalmente eficaz contra o garantismo, que ordinariamente tem sido colocado como forma de "proteção para bandidos", ignorando-se sua principal finalidade de servir como proteção à humanidade. É esse ponto de vista que suporta o discurso populista, que pode ser compreendido como atitude radicalmente pragmática ante os problemas políticos-criminais. São 
"ímpetos enfurecidos" que se afastam dos princípios constitucionais, estabelecendo a interpretação de que as garantias atuam como concessões para que criminosos se favoreçam e não sejam punidos e, devido a isso, de acordo com Elbert, o populismo penal estaria ganhando a batalha contra os defensores do Estado de Direito (ELBERT, 2011, p. 62).

Assim, para melhor entender a atividade política como ação populista, basta considerar que ao se buscar atender aos anseios populares, e mais especificamente os do eleitorado, o populismo cria demandas para oferecer respostas, articulando suas ideias e interesses independentemente de considerações técnicas, mas sacrificando a racionalidade da política criminal em troca de se atingir resultados noutros setores da política, como o eleitoral (PAIVA, 2014, p. 46). Além disso, enfatizou-se que se o que caracteriza o discurso liberal é a proteção da autonomia individual, "quando os populistas assumem o poder, a experiência de transformação da democracia representativa em democracia substantiva, pode, potencialmente, resvalar para práticas autoritárias (ZÚQUETE, 2016, p. 14).

Nessa ordem, considerando a clara influência que o crime opera sobre a realidade, temse, inegavelmente, alterações na condução das instituições da justiça criminal. A exemplo disso, cita-se o programa de policiamento que ficou conhecido como "Tolerância Zero", que passou a servir como paradigma da "boa ordem social". Mas, como consequência de sua dinâmica e do endurecimento das penas e também das formas de controle das infrações menos graves, ocorreu a ampliação substancial da população carcerária não apenas nos Estados Unidos, mas também na maior parte dos países que seguiram dito programa (ALVAREZ; SALLA; GAUTO, 2006, p. 330).

Aliás, no Brasil, que também se serviu dessa ideologia, o direito penal tem sido alçado como único instrumento do controle social capaz de solucionar os problemas da criminalidade (COSTA, 2005, p. 107), e o exemplo disso é dado com a materialização da ação policial. Atente-se que o policial não dispõe de conhecimentos, competências e recursos para dar respostas minimamente adequadas à parcela considerável dos casos que reclamam sua intervenção. Desse modo, vale-se de recursos e métodos penais diversos para contornar os conflitos das mais diversas naturezas. Essa prática ineficaz e na maioria dos casos abusiva, pode ser constatada com o excessivo número de prisões realizadas sem qualquer embasamento jurídico-processual ou investigatório (DIAS NETO, 2003, p. 18). Corroborando essa constatação, Michelle Alexander destacou, em estudo sobre a relação do encarceramento em massa com o racismo, que os "políticos têm tentado justificar as práticas discriminatórias e as altíssimas taxas de encarceramento, argumentando que 
elas são de alguma forma necessárias para lidar com os altos índices de criminalidade em comunidades empobrecidas" (ALEXANDER, 2017, p. 21). Não só por isso, há outro importante fator que deve ser considerado nessa análise, que é a "opinião pública", pois, tratando-se de “instrumento de controle público do poder a partir da expressão do sentimento popular acerca das práticas político-jurídicas adotadas ou a adotar" (STRECK; MORAIS, 2010, p. 191), ela finda por reforçar todos esses desvios e, de certo modo, opera como estimulo favorável às práticas demagógicas exercitadas pelos núcleos dos poderes estatais.

Dito isso, e ainda considerando que o direito penal é expressão da política criminal, em que a discussão sobre os fins e os meios para alcançá-los não pode ser mais que discussão políticocriminal, é imperativo não confundir a prática dessa política com a sua vertente teórica, isso porque, enquanto à primeira correspondem as atividades empíricas, organizadas e ordenadas para a proteção dos indivíduos e da sociedade, a segunda é constituída por um conjunto de princípios teóricos que devem dotar de base racional aquela prática na luta contra o delito (SILVA SÁNCHEZ, 2000, p. 21-23). Com isso, não se pode dizer que no campo do direito penal os fins justifiquem qualquer prática, sendo inconcebível que se faça política criminal apenas com a reunião de projetos legislativos e em meio à pressão avassaladora exercida pelos núcleos midiáticos, sem que a problemática da criminalidade seja adequada e suficientemente analisada e as ações do governo sejam criteriosamente discutidas, planejadas e executadas, sobretudo a partir de parâmetros técnicos, determinados e definidos, entre os quais se deve incluir o sistema padrão de construção de políticas públicas.

A respeito disso, Jorge de Figueiredo desenvolveu minucioso estudo sobre "as instâncias formais de controle no sistema de justiça penal", no qual procurou evidenciar aspectos que vão desde a reação formal ao crime até o papel desempenhado pelos órgãos encarregados da persecução penal, como Polícia, Ministério Público e Poder Judiciário (DIAS; ANDRADE, 1992, p. 365-557). Como, entretanto, a presente pesquisa é um estudo comparativo entre a planificação da política criminal em Portugal e a que se prática no Brasil, é fundamental considerar a importância de se ter uma política dessa natureza bem definida, não apenas em seu sentido formal, mas especialmente em face das relações entre os órgãos que exercem o controle penal destacados nos estudos de Jorge de Figueiredo, para quem é imperativo se alcançar a maximização das estratégias de alianças das diversas instâncias entre si e, também, destas com os setores sociais. Ainda de acordo com o pesquisador lusitano, é crucial dar consistência e previsibilidade ao sistema de controle, além de lhe conferir as condições exigíveis para a consecução de seus propósitos, de modo 
a permitir a realização da justiça penal. Nessa perspectiva, é por intermédio da descoberta dos mecanismos e das regularidades a que se sujeita o processo formal de controle que se conduz a política criminal aos seus propósitos (DIAS; ANDRADE, 1992, p. 390-391).

Com isso, a reunião dos arranjos da política criminal, construída a partir da ordenação e da especialização das funções e da atuação dos órgãos de controle num único corpo legislativo de normas, favorece à coordenação dessa política em razão das regras claras e bem definidas sobre os papéis institucionais (situação de Portugal). Ao contrário, a ausência dessa sistematização faz com que política criminal seja reduzida àquilo que se diz em discursos de ocasião, que têm o objetivo mais acentuado de dar satisfações imediatas à sociedade e à mídia, sem que isso represente verdadeira predisposição de o Estado estabelecer uma política criminal geral, consistente e regular (situação do Brasil). Assim, diante da realidade presente no quadro político e social brasileiro, não há como negar que a classe política confia desmedidamente na lei criminal, como também gosta de invocar sanções penais para os mais variados problemas da ordem social (DIAS; ANDRADE, 1992, p. 414), ao que se convencionou reduzir à fórmula simplista de política criminal.

\section{CONSIDERAÇÕES FINAIS}

A análise de todas estas circunstâncias demonstra que o Estado brasileiro é carecedor de uma política pública específica para a construção das diretrizes quanto à política criminal. Embora a criminalidade seja fato persistente no cotidiano e em todos os níveis do estrato social, não se tem uma sistematização quanto às normas fundamentais que sirvam para orientar o legislador e os administradores públicos em geral, quanto à produção das normas que deverão compor o acervo legislativo da política criminal, que carece, enfim, de rigor técnico e de adequação em face das exigências quanto ao efetivo combate à criminalidade de forma conjugada com o cumprimento dos princípios gerais do ordenamento constitucional, voltados para a proteção dos direitos e das garantias fundamentais individuais.

A falta de um marco legal referenciador da política criminal finda por reduzir todo o discurso da política de enfrentamento da criminalidade a não mais que um conjunto de medidas de ocasião que se definem como propostas de segurança pública, quase sempre empregadas com a finalidade única de dar respostas ao setor especulativo midiático e ao público, mas sem que isso se desdobre em frentes de ação que efetivamente cuidem dos problemas de segurança pública de forma conjugada com uma execução penal que corresponda ao fiel cumprimento das diretrizes 
constitucionais voltadas para a satisfação plena da dignidade da pessoa humana, que tem seus limites definidos pela Constituição Federal.

O "pacote de segurança pública”, que serviu de referencial empírico para este estudo, além de não ter sido previamente estruturado para operar como um conjunto de normas de orientação da política criminal, sequer foi concluído ao final de um ano de atividade parlamentar, evidenciando que as medidas supostamente urgentes de combate à criminalidade, que teriam servido de fundamentação para a formação do referido "pacote", permanecem, ainda, aguardando andamento no âmbito da burocracia política e legislativa.

\title{
COMPARATIVE ANALYSIS OF THE PROCEEDINGS OF CONSTRUCTION OF CRIMINAL POLICY IN BRAZIL AND PORTUGAL
}

\begin{abstract}
The article analyzes the process of creation of the criminal policy by the Brazilian parliament, which combines elements of public security with of criminal, procedural and penitentiary law, treating them jointly as a unique kind of public policy. Evaluates the criteria for the construction of criminal policy as product of decisions that aim to defy rising crime rates and promise respect of the constitutionally protected rights and guarantees. It has as empirical referential the "Framework Law of Criminal Policy", adopted by the Assembly of the Republic of Portugal, which acts as the legal reference for this activity in the Lusitanian State. Methodologically, the study develops in the theoretical-argumentative line and intends, comparatively, to explore and analyze how a specific statute of production of criminal policies can favor the elaboration of normative arrangements more adequate and coherent as the institutional drawings, preserving the integrity of the individual rights, concomitantly with effectivity of public security, assuming that in the Brazilian scenery the great issues of public security and rights and guarantees are rhetorically articulated by populist and occasion's discourse.
\end{abstract}

Keywords: Criminal Policy; Legislative Proceeding; Individual Guarantees; Comparative Analysis

\section{REFERÊNCIAS}

ALEXANDER, M. A nova segregação: racismo e encarceramento em massa. Tradução Pedro Davoglio. São Paulo: Boitempo, 2017. 
ALVAREZ, M C; SALLA, F; GAUTO, M. A contribuição de David Garland: a sociologia da punição. In: Tempo Social: Revista de Sociologia, Universidade de São Paulo, v. 18, n. 1, p. 329350, 2006. Disponível em: <http://www.scielo.br/pdf/ts/v18n1/30020.pdf>. Acesso em: 6 dez. 2018.

BARCELLOS, A L B. Direitos sociais e políticas públicas: algumas aproximações. In: Revista de Direito Público, Londrina, v. 11, n. 2, p. 109-138, ago. 2016. Disponível em: $<$ http://www.uel.br/revistas//uel/index.php/direitopub/article/download/20880/19690>. Acesso em: 4 dez. 2018.

BINDER, A M. Relaciones entre la dogmática penal y la política criminal. In: CÓPPOLA, Patricia (Comp.). Derechos fundamentales y derecho penal. Córdoba: Advocatus, 2006, p. 39-56.

BONAVIDES, P. Do Estado liberal ao Estado social. 7. ed. São Paulo: Malheiros Editores, 2011.

BRASIL. Senado Federal. Projeto de Lei da Câmara n. 140, de 2017. Disponível em: $<$ https://legis.senado.leg.br/sdleg-getter/documento?dm=7264510\&disposition=inline $>$. Acesso em: 3 dez. 2018.

Senado Federal. Projeto de Lei da Câmara n. 141, de 2017. Disponível em: $<$ http://legis.senado.leg.br/sdleg-getter/documento?dm=7265851\&disposition=inline $>$. Acesso em: 3 dez. 2018.

- Senado Federal. Projeto de Lei da Câmara n. 143, de 2017. Disponível em: $<$ https://legis.senado.leg.br/sdleg-getter/documento?dm=7272184\&disposition=inline $>$. Acesso em: 3 dez. 2018.

. Senado Federal. Projeto de Lei da Câmara n. 144, de 2017. Disponível em: $<$ https://legis.senado.leg.br/sdleg-getter/documento?dm=7272214\&disposition=inline $>$. Acesso em: 3 dez. 2018.

Senado Federal. Projeto de Lei da Câmara n. 146, de 2017. Disponível em: $<$ https://legis.senado.leg.br/sdleg-getter/documento?dm=7272318\&disposition=inline $>$. Acesso em: 3 dez. 2018.

Senado Federal. Senado recebe pacote de segurança pública (Notícias Online), Brasília, 16 nov. 2017. Disponível em: <https://www12.senado.leg.br/noticias/materias/2017/ 11/16/senado-recebe-pacote-de-seguranca-publica>. Acesso em: 2 dez. 2018.

BUCCI, M P D. Fundamentos para uma teoria jurídica das políticas públicas. São Paulo: Saraiva, 2013.

Políticas públicas e direito administrativo. In: Revista de Informação Legislativa, Senado Federal, Brasília, v. 33, n. 133, p. 89-98, jan./mar. 1997. Disponível em: $<$ http://www2.senado.leg.br/bdsf/handle/id/198>. Acesso em: 4 dez. 2018.

COCHRAN, C E et al. American public policy: an introduction. 10 $0^{\text {th }}$ ed. Boston: Wadsworth, 2012. Disponível em: <http://www.paconference.ir/uploadfiles/books/AmericanPublic Policy_An_Introduction_Tenth_Edition_2011.pdf $>$. Acesso em: 7 dez. 2018. 
COSTA, Y M R M da. O significado ideológico do sistema punitivo brasileiro. Rio de Janeiro: Revan, 2005.

COUTINHO, D R. O direito nas políticas públicas. In: MARQUES, Eduardo; FARIA, Carlos Aurélio Pimenta de. (Orgs.). A política pública como campo multidisciplinar. São Paulo: Editora Unesp; Rio de Janeiro: Editora Fiocruz, 2013, p. 181-200.

CRUMPTON, C D et al. Evaluation of public policies in Brazil and the United States: a research analysis in the last 10 years. In: Revista de Administração Pública, Rio de Janeiro, v. 50, n. 6, p. 981-1001, nov./dec. 2016. Disponível em: <http://bibliotecadigital.fgv.br/ojs/ index.php/rap/article/download/64711/pdf_89>. Acesso em: 6 dez. 2018.

DIAS NETO, T. Policiamento comunitário e controle sobre a polícia: a experiência norteamericana. 2. ed. Rio de Janeiro: Editora Lumen Juris, 2003.

DIAS, Jorge de Figueiredo; ANDRADE, Manuel da Costa. Criminologia: o homem delinquente e a sociedade criminógena. Coimbra, Portugal: Coimbra Editora, 1992.

DIAS, R; MATOS, F. Políticas públicas: princípios, propósitos e processos. São Paulo: Atlas, 2012.

DIMOULIS, D. Sociedade civil, direitos fundamentais e emancipação: reflexões a partir da obra de Alessandro Baratta. In: ANDRADE, V R P de. Verso e Reverso do Controle Penal: (des) aprisionando a sociedade da cultura punitiva. v. 1. Florianópolis: Fundação Boiteux, 2002, p. 3760.

DUARTE, E C P. Dançando no escuro: apontamentos sobre a obra de Alessandro Baratta, o sistema penal e a justiça. In: ANDRADE, Vera Regina Pereira de. Verso e Reverso do Controle Penal: (des) aprisionando a sociedade da cultura punitiva. v. 2. Florianópolis: Fundação Boiteux, 2002, p. 93122.

ELBERT, C A. O populismo penal: realidade transitória ou definitiva? In: D’ÁVILA, F R (Org.). Congresso Internacional de Direito Penal: Direito Penal e Política Criminal no Terceiro Milênio. Porto Alegre: EDIPUCRS, 2011. Disponível em: <http://ebooks.pucrs.br/ edipucrs/direitopenal.pdf>. Acesso em: 6 dez. 2018.

FERNANDO, D. Police violence as the greatest threat to public security: gendarmerie in Brazil and Mexico. In: The ANU Undergraduate Research Journal, Canberra, Australia, v. 6, p. 73-83, 2014. Disponível em: <http://press-files.anu.edu.au/downloads/press/n1672/pdf/ ch08.pdf $>$. Acesso em: 8 dez. 2018.

FREITAS, R de B A. P. As razões do positivismo penal no Brasil. Rio de Janeiro: Editora Lumen Juris, 2002.

GERALDO, P H B. Direito e políticas públicas: apresentação de um debate (Editorial). In: Revista Ética e Filosofia Política, v. 1, n. 15, p. 1-7, maio 2012. Disponível em: <http://www. ufjf.br/eticaefilosofia/files/2012/05/15_1_barrosgeraldo1.pdf>. Acesso em: 4 dez. 2018.

GLOECKNER, R J; RAMOS, M B. Os sentidos do populismo penal: uma análise para além da condenação ética. In: Delictae: Revista de Estudos Interdisciplinares sobre o Delito, PUC Minas vol.12,nº.03,RiodeJaneiro,2019. pp. 588-611 608 
Gerais, v. 2, n. 3, p. 248-297, jul./dez. 2017. Disponível em: <http://www.delictae.com. br/index.php/revista/article/view/39/36>. Acesso em: 6 dez. 2018.

GUINDANI, M. Sistemas de política criminal no Brasil: retórica garantista, intervenções simbólicas e controle social punitivo. In: Cadernos CEDES/IUPERJ, Rio de Janeiro, n. 2, p. 2-20, 2006. Disponível em: $\quad<$ http://www.cis.puc-rio.br/cis/cedes/PDF/cadernos/cadernos\% 202\%20-\%20sistemas\%20politica\%20criminal.pdf $>$. Acesso em: 6 dez. 2018.

IDRISS, $\mathrm{M}$ et al. International report on crime prevention and community safety: trends and perspectives. Montreal, Canada: International Centre for the Prevention of Crime, 2010. Disponível em: $\quad<$ http://www.crime-prevention-intl.org/fileadmin/user_upload/Publications/ Crime_Prevention_and_Community_Safety_ANG.pdf>.Acesso em: 8 dez. 2018.

LASCOUMES, P; LE GALES, P. Introduction: understanding public policy through its instruments: from the nature of instruments to the sociology of public policy instrumentation. In: Governance: An International Journal of Policy, Administration, and Institutions, v. 20, n. 1, p. 121, jan. 2007. Disponível em: <http://www.sociologia.unimib.it/DATA/Insegnamenti/ 2_1939/materiale/lascumesle\%20gales.pdf>. Acesso em: 7 dez. 2018.

LIMA, L; D’ASCENZI, Luciano. Estrutura normativa e implementação de políticas públicas. In: MADEIRA, L M (Org.). Avaliação de Políticas Públicas. Porto Alegre: CEGOV, 2014, p. 50-63. Disponível em: $\quad<$ http://www.lume.ufrgs.br/bitstream/handle/10183/ 108186/000948569.pdf? sequence=1>. Acesso em: 7 dez. 2018.

MORAES, M Z de. Política criminal, constituição e processo penal: razões da caminhada brasileira para a institucionalização do caos. In: Revista da Faculdade de Direito, Universidade de São Paulo, v. 101, p. 403-430, jan./dez. 2006. Disponível em: <https://www. revistas.usp.br/rfdusp/article/download/67712/70320>. Acesso em: 6 dez. 2018.

MORAIS, J L B de; BRUM, G V. Políticas públicas e jurisdição constitucional: entre direitos, deveres e desejos. Porto Alegre: Livraria do Advogado, 2016.

MOUFFE, C. La paradoja democrática. Tradução Tomás F. Aúz y Beatriz Eguibar. Barcelona: Editorial Gedisa, 2003.

MUÑOZ TEJADA, J A. Populismo punitivo y una "verdad" construida. In. Nuevo Foro Penal, Antioquia, Colombia, v. 5, n. 72, p. 13-42, ene./jun. 2009. Disponível em: <http:// publicaciones.eafit.edu.co/index.php/nuevo-foro-penal/article/view/1856/1856>. Acesso em: 6 dez. 2018.

MURDA, P F V N. Políticas públicas: o controle judicial e o papel das funções essenciais à justiça. Curitiba: Editora Prismas, 2015.

NWAGBOSO, C I. Public policy and the challenges of policy evaluation in the Third World. In: British Journal of Humanities and Social Sciences, v. 5, n. 1, p. 59-76, apr. 2012. Disponível em: $<$ http://www.ajournal.co.uk/HSpdfs/HSvolume5(1)/HSVol.5\%20(1)\%20

Article\%207.pdf>. Acesso em: 6 dez. 2018. 
OHLWEILER, L. A construção e implementação de políticas públicas: desafios do direito administrativo moderno. In: Verba Juris, Universidade Federal da Paraíba, a. 6, n. 6, p. 269-300, jan./dez. 2007. Disponível em: <http://periodicos.ufpb.br/index.php/vj/article/viewFile/ 14868/8423>. Acesso em: 4 dez. 2018.

ORGANIZATION OF AMERICAN STATES. Public security in the Americas: challenges and opportunities. $2^{\text {nd }}$ ed. Washington, DC: Official Records Series, 2008. Disponível em: $<$ https://www.oas.org/dsp/PDFs/oea2_final_baja_ing.pdf >. Acesso em: 6 dez. 2018.

PAIVA, L G M de. Populismo penal no Brasil: do modernismo ao antimodernismo penal. 2014. 178 f. Tese (Doutorado em Direito) - Faculdade de Direito, Universidade de São Paulo. Disponível em: $\quad<\mathrm{http} / /$ www.teses.usp.br/teses/disponiveis/2/2136/tde-31012017-162325/ publico/Tesecompleta.pdf $>$. Acesso em: 6 dez. 2018.

PORTUGAL. Assembleia da República. Lei n. 17, de 23 de maio de 2006. Diário da República, $1^{\mathrm{a}}$ Série-A, n. 99. Disponível em: <http://www.dgpj.mj.pt/DGPJ/sections/leis-da-justica/livro-iv-leiscriminais/pdf4/1-17-2006/downloadFile/file/L_17_2006.pdf?nocache= 1182174456.09>. Acesso em: 3 dez. 2018.

. Assembleia da República. Lei n. 51, de 31 de agosto de 2007. Diário da República, $1^{\mathrm{a}}$ Série, n. 168. Disponível em: <http://www.dgpj.mj.pt/sections/informacao-e-eventos/2007/lei-n51-2007-de-31-de/downloadFile/file/L_51_2007.pdf?nocache= $1188553649.75>$. Acesso em: 5 dez. 2018.

RAAD, M R. Uma análise da política criminal sob o enfoque do direito penal do terror. Pontifícia Universidade Católica do Rio Grande do Sul, 2006. Disponível em: <http://www3. pucrs.br/pucrs/files/uni/poa/direito/graduacao/tcc/tcc2/trabalhos2006_1/marco.pdf $>$. Acesso em: 6 dez. 2018.

REKERS, R F. Populismo y castigo penal. In: Revista Pensamiento Penal, p. 1-14, oct. 2012. Disponível em: <http://www.pensamientopenal.com.ar/system/files/2012/10/doctrina34815. pdf $>$. Acesso em: 6 dez. 2018.

SALDANHA, N. Formação da teoria constitucional. 2. ed. Rio de Janeiro: Renovar, 2000.

SILVA SÁNCHEZ, J M. Politica criminal y persona. Buenos Aires: Ad-hoc, 2000.

SNOWDON, A. Evaluation public policy grantmaking: a resource for funders. In: Goldman School of Public Policy, University of California Berkeley, p. 1-46, jun. 2004. Disponível em: $<\mathrm{http} / / /$ www.pointk.org/resources/files/evaluating_PPGM.pdf $>$. Acesso em: 6 dez. 2018.

SOARES, L E. Public security: present and future. In: Revista Estudos Avançados, São Paulo, v. 21, n. 56, p. 91-106, jan./abr. 2007. Disponível em: <http://www.scielo.br/pdf/ea/v20n56/ 28629.pdf>. Acesso em: 6 dez. 2018.

STRECK, L. L; MORAIS, J L B de. Ciência política e teoria do Estado. 7. ed. Porto Alegre: Livraria do Advogado, 2010. 
TREVISAN, A P; BELLEN, H M V. Avaliação de políticas públicas: uma revisão teórica de um campo em construção. In: RAP, Rio de Janeiro, v. 42, n. 3, p. 529-550, maio/jun. 2008. Disponível em: $<$ http://www.scielo.br/pdf/rap/v42n3/a05v42n3.pdf $>$. Acesso em: 7 dez. 2018.

ZÚQUETE, J P. Era uma vez o populismo. In: Revista Relações Internacionais: Populismo e Migrações, Lisboa, n. 50, p. 11-22, jun. 2016. Disponível em: <http://www.scielo.mec.pt/pdf/ ri/n50/n50a02.pdf >. Acesso em: 6 dez. 2018.

Trabalho enviado em 18 de dezembro de 2018

Aceito em 13 de março de 2020 